\title{
Interseksionalitas Pengalaman Perempuan Toraja: Sebuah Konstruksi Teologi Feminis Melalui Ritus Ma' Bua' Kasalle
}

Vani Mega Rianna Mantong Tendenan

Sekolah Tinggi Filsafat Theologi Jakarta

vanimantong@gmail.com

D01: https://doi.org/10.34307/b.v4i2.287

\begin{abstract}
This paper discusses the Toraja ritual, namely ma' bua' kasalle as a life thanksgiving ceremony which then becomes the basis for offering a feminist theological perspective, regarding the intersectionality of women's experiences in ritual. The method used in this article is a qualitative method with an analytical description approach that brings together Ronald L. Grimes' thoughts on ritual as a bodily experience with Denise $L$. Carmody's thoughts on women's experiences rooted in the experience of the Christian faith. The aim is to provide a feminist theological perspective that the intersectionality in the experience of Toraja women results in an attempt at equality in cultural rituals such as $\mathrm{ma}^{\prime}$ bua' kasalle. The results show that the intersectionality of the experiences of Toraja women occurs through the first pa'gellu' dance, the second group of nani and simbong songs and the third is the placement of the fallen women who are in the tower. The three representations have created a dynamic and inclusive space for action, language and relations. The interaction between the experiences of Toraja women is a source of selfempowerment and community. The thesis statement of this paper is that the intersectionality of the Toraja women's experience means a social interaction that involves the role of women with all their existence including faith, perspective and presence as an effort to equal women in culture.
\end{abstract}

Keywords: intersectionality, women's experiences; ritual; ma' bua' kasalle; Toraja culture

Abstrak: Tulisan ini membahas tentang ritual Toraja yaitu $\mathrm{ma}^{\prime}$ bua' kasalle sebagai upacara syukuran kehidupan yang kemudian menjadi dasar untuk menawarkan perspektif teologi feminis, tentang interseksionalitas pengalaman perempuan dalam ritual. Metode yang digunakan dalam artikel ini ialah metode kualitatif dengan pendekatan deskripsi analitis yang mempertemukan pemikiran Ronald L. Grimes tentang ritual sebagai pengalaman tubuh dengan pemikiran Denise L. Carmody tentang pengalaman perempuan yang berakar pada pengalaman iman Kristen. Tujuannya adalah untuk memberikan perspektif teologis feminis bahwa interseksionalitas dalam pengalaman perempuan Toraja menghasilkan upaya kesetaraan dalam ritual budaya seperti $m a^{\prime}$ bua' kasalle. Hasil penelitian menunjukkan interseksionalitas pengalaman perempuan Toraja terjadi melalui pertama tari pa'gellu', kedua kelompok nyanyian nani dan simbong dan ketiga adalah penempatan tumbang perempuan yang berada di menara. Ketiga representasi tersebut telah menciptakan ruang aksi, bahasa dan 
relasi yang dinamis dan inklusif. Interaksi antar pengalaman perempuan Toraja menjadi sumber pemberdayaan diri dan komunitas. Pernyataan tesis makalah ini ialah interseksionalitas pengalaman perempuan Toraja berarti suatu interaksi sosial yang melibatkan peran perempuan dengan segala keberadaan dirinya termasuk iman, perspektif dan kehadirannya sebagai upaya kesetaraan perempuan dalam budaya.

Kata Kunci: interseksionalitas, pengalaman perempuan; ritual; $m a^{\prime}$ bua' kasalle; budaya Toraja

\section{Pendahuluan}

Ritual merupakan serangkaian tindakan yang dikhususkan dalam memaknai peristiwa kehidupan. Dalam praktiknya, ritual dapat ditemui melalui keragaman konteks dan budaya yang dilaksanakan baik secara individu maupun kelompok. Setiap daerah di Indonesia memiliki berbagai ritual yang terbentuk pada keragaman konteks budaya, Keragaman konteks yang menyimbolkan suatu makna dan bahasa membentuk ritual menjadi menarik. Ritual menampilkan berbagai realitas kehidupan manusia yang dapat menghasilkan pemberdayaan bagi kehidupan bersama. Namun tidak dapat dipungkiri bahwa ritual dapat meminggirkan keterlibatan pengalaman perempuan.

Komisi Nasional Anti Kekerasan Terhadap Perempuan (Komnas Perempuan) dalam kajian kekerasan terhadap perempuan berbasis budaya di beberapa wilayah di Indonesia menemukan bahwa upacara perkawinan secara adat telah memerlihatkan dampak yang mengarah pada kekerasan terhadap perempuan. ${ }^{1}$ Ritual budaya yang tersirat dalam upacara perkawinan tidak bebas dari potensi munculnya ruang-ruang kekerasan terhadap perempuan. Pada sisi yang lain, penelitian yang dilakukan oleh Eymal B. Demmallino menemukan ritual budaya memiliki pengaruh yang signifikan terhadap meningkatnya kekerasan kepada pekerja migran.

"Faktor kultural menjadi salah satu penyebab yang membuat banyaknya pekerja migran dari Sulawesi Selatan menempuh jalur ilegal dan kemudian menyeret para migran yang sebagian besar adalah perempuan mengalami berbagai bentuk eksploitasi yaitu penindasan ekonomi hingga pelacuran." ${ }^{2}$

Faktor kultural merujuk kepada praktik budaya yang mengalami pergeseran, seperti upacara kematian yang menciptakan kewajiban kultural sehingga mendorong

\footnotetext{
1 "Pemetaan, Kajian, \& Prosiding," Komnas Perempuan | Komisi Nasional Anti Kekerasan Terhadap Perempuan, diakses 1 Mei 2021, diakses 10 November 2021, https://komnasperempuan.go.id/pemetaankajian-prosiding-detail/kekerasan-terhadap-perempuan-berbasis-budaya.

2 Eymal B. Demmallino, Utang budaya perempuan Tana Toraja (Kerja sama Ford Foundation dengan Pusat Studi Kependudukan dan Kebijakan, Universitas Gadjah Mada, Yogyakarta, 2004), 3-4.
} 
para perempuan untuk bermigrasi dan memperoleh pekerjaan agar dapat membiayai ritual budaya di Toraja. Kewajiban kultural menyangkut keikutsertaan menyumbang kerbau atau persembahan yang akan dikurbankan dalam ritual, kewajiban ini berkaitan erat dengan biaya yang dibebankan kepada keluarga yang melaksanakan. Dalam hal ini, persepsi terhadap ritual budaya memberikan pengaruh terhadap praktik ritual yang menjadi tidak sejalan dengan esensi kebaikan dari kebudayaan. Sejalan dengan konteks penelitian tulisan ini, pergeseran terhadap konsep ritual budaya dapat menjadi praktik yang kurang melibatkan pengalaman perempuan. Posisi perempuan yang marjinal dalam masyarakat memengaruhi keterlibatan liminalitas perempuan yang memiliki perbedaan dengan laki-laki dalam ritual. ${ }^{3}$ Jan Berry, seorang ahli teologi praktis dari Inggris menggunakan teori liminalitas dari Victor Turner untuk menunjukkan ambiguitas posisi perempuan dalam ritual budaya karena perspektif yang dominan ialah laki-laki. Kondisi ini memunculkan suatu pertanyaan, yakni bagaimana keberadaan perempuan dan pengalamannya dalam ritual secara khusus dalam ritual budaya Toraja? Adakah ritual berbasis budaya yang dapat menjadi ruang yang adil dan setara untuk perempuan dengan pengalamannya? Pertanyaan ini kemudian menjadi polemik tersendiri bagi penulis untuk meneliti salah satu bentuk ritual budaya Toraja yang juga menjadi pembatasan masalah dalam tulisan ini yaitu ritual $m a^{\prime}$ bua' kasalle. Tujuan penelitian terhadap ritual $m a^{\prime} b^{\prime} a^{\prime}$ kasalle ialah untuk membangun perspektif teologis feminis melalui penerimaan pengalaman perempuan dalam ritual sebagai dasar untuk memperjuangkan keadilan dan kesetaraan dalam ritual budaya.

Masyarakat Toraja secara tradisional memiliki agama yang dikenal sebagai Aluk Nene'. Dalam rangkaian ritual adat yang diberlakukan orang Toraja hingga saat ini, Aluk Nene' memegang peranan penting terhadap pembentukan makna, simbol, bahasa dan media yang digunakan dalam ritual. Dalam adat Toraja terdapat dua ritual besar yang menjadi simbol kehidupan masyarakat Toraja, yaitu aluk rambu solo' dan aluk rambu tuka'. Aluk rambu solo' berarti upacara adat yang berhubungan dengan ritus kematian sedangkan aluk rambu tuka' ialah keseluruhan ritus persembahan untuk kehidupan. ${ }^{4}$

Makalah ini memanfaatkan penelitian yang dilakukan oleh Dana Rappoport, seorang etnomusikologi asal Prancis, terhadap musik ritual Toraja yang terdapat dalam ritus-ritus besar masyarakat Toraja, salah satunya adalah ritus bua' kasalle sebagai bagian dalam ritual aluk rambu tuka'. Upacara ma' bua' kasalle merupakan upacara syukur dalam budaya Toraja yang hanya dilakukan ketika sebuah keluarga telah melaksanakan aluk rambu solo' tingkat paling tinggi yaitu rapasan. ${ }^{5}$ Ritus ini menampilkan perayaan syukuran atas kehidupan sekaligus menjadi media untuk mendoakan kesuburan

\footnotetext{
${ }^{3}$ Jan Berry, “Whose Threshold? Women's Strategies of Ritualization," Feminist Theology 14, no. 3 (Mei 2006): 275, https://doi.org/10.1177/0966735006063769.

${ }^{4}$ Theodorus Kobong, Injil dan Tongkonan: Inkarnasi, Kontekstualisasi, Transformasi -, trans. oleh Th. van den End dan Theodorus Kobong, Cet. 2 (Jakarta: BPK Gunung Mulia, 2020), 48-54.

${ }^{5}$ Bentuk tingkatan tertinggi dalam upacara kematian yang dilakukan oleh golongan bangsawan.
} 
tanaman, pemeliharaan ternak, rumah dan ikatan keturunan dalam keluarga. Prosesi $m a^{\prime}$ bua' kasalle menawarkan sebuah konstruksi teologi feminis karena menyiratkan ritus yang menghadirkan perempuan dan laki-laki sebagai pelaku ritual yang setara. Makalah ini terdiri empat bagian. Pertama penulis akan mendeskripsikan tentang ritus $m a^{\prime}$ bua'. Kedua, penulis akan memaparkan proses pengalaman perempuan Toraja yang dimulai dari tarian dan nyanyian dalam ritus $m a^{\prime} b u a^{\prime}$ kasalle. Ketiga, penulis akan memaparkan pengalaman perempuan Toraja yang berlanjut kepada simbol kedudukan tertinggi untuk perempuan. Pada bagian terakhir, penulis mencoba memaparkan interaksi pengalaman perempuan Toraja dalam analisis interseksinalitas. Kemudian penulis melakukan refleksi terhadap konsep pengalaman perempuan dalam perjumpaan dengan Yesus sebagai basis perspektif untuk dialog antara kebudayaan dengan teologi feminis.

\section{Metode Penelitian}

Metode penelitian yang digunakan dalam makalah ini ialah metode kualitatif dengan pendekatan deskripsi analitis dan studi literatur. Penelitian kualitatif terdiri dari seperangkat praktik interpretif yang menempatkan peneliti pada realitas di dunia dalam memahami, menafsirkan fenomena untuk menghasilkan suatu makna. ${ }^{6}$ Penelitian kualitatif merujuk pada upaya penulis untuk menemukan makna serta perspektif baru yang dapat dipahami dari praktik ritus $m a^{\prime}$ bua' kasalle. Pendekatan deskripsi analitis dilakukan dengan memaparkan terlebih dahulu konteks ritus ma' bua' kasalle untuk selanjutnya dianalisis dari perspektif ritual feminis dengan menggunakan pemikiran antara Ronald L. Grimes dan Denise L. Carmody. Grimes secara spesifik menggambarkan ritual dalam konsep imagining sebagai serangkaian tindakan yang terdiri dari imajinasi yang dinamis dan tidak dapat dibatasi dalam kebakuan institusi dan konsep inventing yang berarti ritual menemukan, menciptakan kembali ruang-ruang perwujudan dari imajinasi yang secara terus menerus dapat mengalami perubahan. ${ }^{7}$ Ritual menampilkan pengalaman tubuh manusia yang terus bergerak sejalan dengan pengalaman yang berbeda dari setiap individu. Kemudian, Carmody dalam kesejajaran perspektif membangun konstruksi teologi feminis Kristen dengan melibatkan pengalaman perempuan yang bersumber dari dasar kehidupan iman Kristen, yaitu pencarian keadilan, makna, keindahan, dan kasih. ${ }^{8}$ Perspektif feminis Kristen menekankan pengalaman perempuan bukan dalam arti menyingkirkan laki-laki melainkan sebagai bentuk upaya kesetaraan penuh dalam pengalaman iman baik perempuan maupun laki-laki. Data dalam

\footnotetext{
${ }^{6}$ Norman K Denzin dan Yvonna S Lincoln, The SAGE Handbook of Qualitative Research (California: SAGE Publications, 2018), 43.

7 Ronald L. Grimes, Deeply into the Bone: Re-Inventing Rites of Passage, Life Passages (Berkeley: University of California Press, 2000), 4.

8 Denise L. Carmody, Christian Feminist Theology: A Constructive Interpretation (Cambridge: University of California Press, 1995), 15-29.
} 
penulisan ini bersumber dari studi literatur baik itu melalui buku-buku, artikel, informasi dari situs web, serta hasil-hasil penelitian yang berkaitan dengan topik penulisan.

\section{Hasil dan Pembahasan}

Dalam kepercayaan Aluk Nene', ritual yang berhubungan dengan aluk rambu tuka' ditujukan kepada para dewa dan kepada leluhur yang telah menjadi dewa (to membali puang), yang mendiami langit sebelah timur laut. ${ }^{9}$ Persembahan dalam ritual syukuran ini memiliki relasi dengan ritual kematian karena menyangkut kepercayaan pada leluhur yang diyakini dapat menjadi dewa. $M a^{\prime} b u a^{\prime}$ kasalle dalam budaya Toraja mengalami dinamika perubahan seiring berjalannya waktu serta konteks keagamaan masyarakat Toraja yang saat ini mayoritas beragama Kristen. Prosesi $m a^{\prime} b u a^{\prime}$ kasalle yang dilakukan oleh Aluk Nene', menghabiskan waktu yang cukup lama yaitu satu tahun, berbeda dengan orang Toraja saat ini yang melakukan ritus $m a^{\prime} b u a^{\prime}$ kasalle, hanya dalam jangka waktu tiga hari.

\section{Ritus Ma' Bua' Kasalle}

Dalam pandangan umum, ritus $m a^{\prime}$ bua' kasalle diartikan sebagai persekutuan kampung, yang dilakukan secara gotong royong untuk memohon berkat bagi kehidupan manusia, hewan, tanah, dan tanam-tanaman. ${ }^{10}$ Ritus ini kemudian terbagi ke dalam beberapa bagian yang disesuaikan dengan doa yang ingin ditujukan dalam ritus. Akan tetapi dalam praktiknya, ritus ini menyatukan berbagai permohonan berkat.

$M a^{\prime}$ bua' kasalle kemudian tergolong sebagai salah satu ritus besar dalam masyarakat Toraja karena menghabiskan biaya yang besar untuk mempersiapkan persembahan-persembahan syukur berupa hewan. Persembahan syukur yang ada dalam ritus ini menandakan status sosial keluarga yang mengadakan $m a^{\prime}$ bua' kasalle. Semakin tinggi status sosial keluarga dalam masyarakat maka semakin banyak hewan yang dipersembahkan. Tetapi tetap memiliki batasan, misalnya untuk upacara adat bangsawan ialah 24 ekor kerbau. Dalam tradisi Aluk Nene', ritus ini hanya dapat dilakukan oleh keluarga-keluarga bangsawan yang telah melaksanakan ritus rambu solo' terbesar. ${ }^{11}$ Ritual kehidupan dan kematian menjadi saling berelasi, keduanya berkewajiban memenuhi ritual adat yang sesuai dengan struktur sosial agar leluhur dapat memberi berkat kembali kepada keturunannya. Menurut kepercayaan Aluk Nene', terdapat dua alasan diadakannya ritus $m a^{\prime} b u a^{\prime}$, pertama menyangkut keselamatan dari bahaya besar

9 Theodorus Kobong, Injil dan Tongkonan: Inkarnasi, Kontekstualisasi, Transformasi -, 48-54.

10 Ibid.

11 Dana Rappoport, Nyanyian Tana Diperciki Tiga Darah: Penceritaan Etnografi, trans. oleh Stanislaus Sandarupa (Jakarta: Yayasan Pustaka Obor Indonesia, 2020), 76. 
dan kedua berkaitan dengan penghapusan dosa. ${ }^{12}$ Ritus syukur ini berfungsi sebagai mediasi bagi kesalahan serta keselamatan yang telah diterima seseorang.

Waktu untuk pelaksanaan ritus ini dilakukan selama setahun, ditandai dengan adanya jeda waktu selama beberapa bulan untuk persiapan yang dilakukan keluarga.

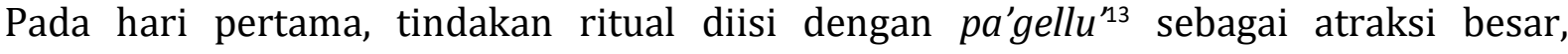
perempuan-perempuan menari diiringi gendang. Terdapat juga beberapa anggota keluarga besar yang berperan dalam ritus $m a^{\prime} b u a^{\prime}$. Peran mereka dalam ritus ini tidak hanya berdampak pada pelaksanaan ritual, namun terjadi juga perubahan identitas mereka dalam masyarakat.

Beberapa peran keluarga besar (rapu) dalam $m a^{\prime}$ bua' yang identitasnya berubah adalah: ${ }^{14}$

a. Empat perempuan tua disebut tumbang tua. Tumbang ialah perempuan yang dipingit secara khusus untuk melakukan pemujaan kepada deata.

b. Seorang perempuan berusia sedang disebut tumbang muda, para tumbang bersama pemangku adat menjalankan serangkaian pantangan makan.

c. Dua perempuan limbong bua' yang akan melakukan persembahan atau sajian dan pondok bua' berperan sebagai wakil dari perempuan tumbang. Para perempuan mengenakan pakaian berwarna kuning.

d. Seorang to manobok yang menggunakan tanduk berperan sebagai pengantar para penari masuk.

e. Para penari menggunakan tanduk disebut to manganda', orang yang menabuh gendang disebut to ma'gandang

f. Pembantu pemangku adat disebut burake.

Adapun pembagian peran tersebut menentukan penamaan yang berlaku sepanjang umur bagi mereka yang berperan. Peran-peran yang ada menunjukkan

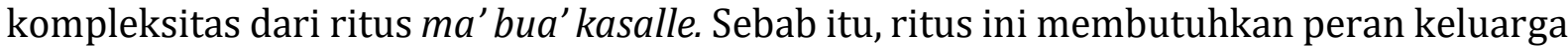
yang sesuai dengan rangkaian prosesi dari ritus ini. Tempat pelaksanaan ritus ini dilakukan di Tongkonan ${ }^{15}$ atau lapangan luas (kala'paran). Hewan kurban yang dipersembahkan dalam ritus ini kurang lebih 80 ekor babi dan 2 kerbau. Sepanjang ritus, beberapa perempuan dilantik, dipuja, dinyanyikan, digendong dan seorang perempuan tumbang yang akan tinggal selama beberapa malam di atas menara yang tinggi dari Tongkonan (pentiroan lalan rongko'), tempat pelaksanaan ritus. ${ }^{16}$ Menara merupakan pusat tempat pelaksanaan ritus.

12 Kees Buijs, To Burake Imam Perempuan Pelayan Adat Tertinggi: Ritual dan Ucapannya dalam Agama Tradisional Masyarakat Toraja Mamasa, ed. oleh Anwar Jimpe Rachman (Makassar: Ininnawa, 2020), 195-196.

13 Tarian tradisional budaya Toraja

${ }^{14}$ Rappoport, Nyanyian Tana Diperciki Tiga Darah, 76-77.

${ }^{15}$ Rumah adat Toraja

${ }^{16}$ Rappoport, Nyanyian Tana Diperciki Tiga Darah,, 77. 
$M a^{\prime}$ bua' kasalle dipimpin oleh pemangku adat yang menyampaikan syair-syair permohonan. Syair dimulai dari permohonan agar terhindar dari segala penyakit, kemudian berlanjut ke kesuburan tanah, hewan dan rumah. Syair disampaikan dalam bentuk nyanyian dengan nada datar. Pemangku adat dibantu oleh kelompok bernyanyi yang disebut sebagai nani (kaum perempuan) dan simbong (kaum laki-laki). Kedua kelompok bernyanyi tersebut memiliki kekhasan nyanyian tanpa ketukan irama, panjang tak putus-putus, dilakukan sambil duduk, dan pada bagian akhir terdapat ungkapan yang diulangi (kurre-kurre sumanga'=syukur-syukur). ${ }^{17}$ Ritus $m a^{\prime}$ bua' kasalle menggambarkan bentuk ritual perayaan akan kehidupan, ungkapan syukur yang tidak dapat disederhanakan karena setiap tindakan dalam ritual menyimbolkan makna serta bahasa keyakinan yang khas dari Aluk Nene'.

\section{Tarian Pa'gellu' sebagai Simbol Kehidupan}

Ritus $m a^{\prime}$ bua' kasalle berisi rangkaian tindakan ritual yang saling terkait satu sama lain yang didasari bentuk syukuran atas kehidupan, pemeliharaan serta permohonan berkat kepada deata. Sebuah ritual menjadi bermakna ketika ada serangkaian tindakan mewujud dalam pandangan manusia karena tanpa wujud sebuah ritual sulit untuk dipraktikkan bahkan dapat bertahan. Ronald L. Grimes, seorang ahli teori ritual asal Amerika Serikat, dalam tulisannya The Craft of Ritual Studies memberikan penekanan pada ritual secara inklusif, adanya keterlibatan sistem dan tradisi dalam membangun ritual. Ritual merupakan serangkaian proses yang dirancang dan saling terkait, bekerja secara terintegrasi dan dinamis, bagian-bagian ritual seperti tubuh dan sepeda. ${ }^{18}$

Grimes menggunakan metafora tubuh yang terdiri atas beberapa bagian seperti sepeda, terdapat perantara yang saling terkait untuk bagian lainnya. Metafora ini menunjukkan bahwa meskipun ritual itu dirancang bukan berarti ritual itu menjadi tertutup dari dunia luar. Grimes memperkenalkan action (aksi) sebagai salah satu dari tujuh elemen ritual yaitu aktor, tempat, waktu, objek, bahasa, dan grup untuk menganalisis ritual. ${ }^{19}$ Dalam aksi ritual, setiap tindakan, ritme, gaya dan gerakan tubuh menjadi perhatian utama yang berguna untuk membangun sebuah ritual.

Masyarakat Toraja mengidentikkan tarian $\mathrm{pa}^{\prime}$ gellu ${ }^{20}$ dengan ritus $\mathrm{ma}^{\prime}$ bua' kasalle. Tarian merupakan aksi untuk mencapai tujuan ritual dan menjadi menarik secara visual. Sebab, tarian ini menampilkan gerakan tubuh perempuan. Tarian pa'gellu' memiliki lima ragam gerak yang masing-masing menyimbolkan makna tersendiri. Berdasarkan

\footnotetext{
17 Ibid., 79-81.

18 Ronald L. Grimes, The Craft of Ritual Studies (Oxford; New York: Oxford University Press, USA, 2013), 234.

19 Ibid., 237.

20 Tarian yang hingga saat ini ditarikan dalam upacara syukuran lainnya.
} 
penelitian yang telah dilakukan Intan Sari Matasak terhadap tarian ini, maka ia menemukan rangkaian simbol serta makna dari ragam gerak. ${ }^{21}$

- Gerak pertama disebut dena'-dena' (burung pipit) yang menyimbolkan burung pipit sebagai makna dari kehidupan yang dibangun secara bersama-sama dengan mengupayakan kerjasama serta persatuan.

- Gerak kedua disebut gellu' tua (tarian tua) menyimbolkan tanda penghormatan kepada deata dan penghormatan bagi orang lain.

- Gerak ketiga yaitu pa'tulekken (menyangga tangan di pinggang) sebagai simbol waktu istirahat yang bermakna memberi jeda bagi tubuh dari segala aktivitas.

- Gerak keempat yaitu pasirri (memilah, mengumpulkan) simbol perempuan menampi beras yang bermakna kehidupan diperhadapkan pada pilihan sehingga manusia diharapkan dapat memilih yang baik.

- Gerak kelima ialah pa'ra'pak pentallun (gerakan patahan tiga kali) menyimbolkan air sebagai sumber kehidupan, api sebagai sumber berkat, dan udara sebagai sumber nafas.

Tarian yang menyentuh dari ranah privat kepada publik ini menampilkan perempuan adalah keterwakilan dari masyarakat sebagai tubuh sosial yang memerlukan media untuk mengomunikasikan bahasa dalam berelasi dengan pencipta. Iris J. Stewart seorang penari sekaligus ahli studi feminis, menggunakan pendekatan spiritualitas dan feminis dalam menggali keterkaitan tarian dengan perempuan. Tarian menunjukkan suatu ekspresi manusia yang abadi, menjadi bahasa yang melampaui kata dan pikiran. Bahkan tarian dalam ritual mampu menciptakan komunitas, mempersatukan individu secara emosional, dan fisik dalam keintiman. ${ }^{22}$ Sebagai aksi ritual, tarian menghasilkan ruang terbuka bagi pengalaman komunitas untuk melebur dalam kebersamaan, karena tarian tidak hanya sebatas pengamatan visual dari penonton, melainkan merujuk juga kepada pengalaman tubuh yang mengkonfirmasi kreativitas, imajinasi serta praktik ritual yang menghidupkan. Sepadan dengan pemikiran Stewart, Grimes melihat bahwa ritual menjadi sangat sensual, melibatkan unsur-unsur penggerak tubuh termasuk hati karena

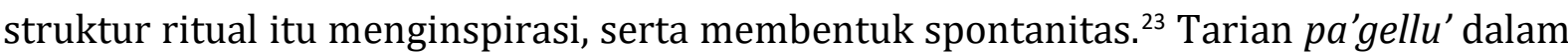
realitasnya memang dapat diajarkan dan dilatih, tetapi ketika masuk dalam ritual, tarian pa'gellu' mengundang kepekaan bagi setiap orang yang terlibat untuk mengalami ritual.

Menurut penulis, jika tarian $\mathrm{pa}^{\prime}$ gellu' yang ditampilkan dalam ritus ma' bua' kasalle sebagai aksi pembuka, maka tarian ini menjadi penanda khusus untuk keberlanjutan aksi yang lain. Dalam aksi tarian ini, perempuan dipilih dalam menarikan simbol burung pipit,

21 Intan Matasak Sari, "Makna Simbolik Pa'gellu' Tua di Desa Pangala' Kabupaten Toraja Utara”” (Skripsi S.Sn, 2020), 3-5,

22 Iris J Stewart, Sacred Woman Sacred Dance: Awakening Spirituality Through Movement and Ritual (Rochester: Inner Traditions, 2013), 14-15

23 Grimes, Deeply into the Bone, 344. 
penghormatan, waktu jeda, menampi beras serta unsur-unsur alam yang menjadi penanda khusus bagi gerakan tarian, penguatan akan keindahan ritual yang melekat dalam ritus ma' bua' kasalle. Carmody melihat keindahan tidak terbatas pada bentuk fisik, melainkan dalam pengalaman iman, keindahan dapat ditemui melalui fenomena yang terstruktur serta bentukan dari alam atau budaya. ${ }^{24}$ Simbol dalam tarian pa'gellu' menyatakan pengalaman keindahan bersama, antara manusia, alam dan Tuhan yang disembah. Pencarian akan keindahan menampilkan aksi ritual menjadi aksi bersama dengan partisipan, dalam hal ini masyarakat yang hadir, meskipun yang bergerak dalam aksi ritual adalah perempuan. Makna tarian tidak hanya berfokus pada membangun keterarahan dengan pencipta, melainkan identitas individu, orang lain, serta alam saling berinteraksi mewujudkan tarian syukur.

Stewart melihat tarian dan perempuan memiliki konektivitas dalam spiritualitas yang menciptakan kekuatan kehidupan dan menghasilkan kesempatan untuk setiap ekspresi jiwa individu. ${ }^{25}$ Analisis ini tidak hanya didasarkan pada pengetahuan tarian, melainkan berdasar pada temuannya pada tarian dan perempuan yang telah terdistorsi dari sejarah religius. Sejarah cenderung pada upaya interpretasi atau penceritaan terhadap sebuah peristiwa dibandingkan upaya menandai tarian sakral yang sudah berkembang dalam sejarah religius sehingga "women's voice has so often been absent". ${ }^{26}$ Tarian tidak hanya bernilai sakral, melainkan juga menyimbolkan suara perempuan dalam praktik budaya. Sebab itu, Stewart berupaya mengembalikan tarian sebagai kesenian yang dekat dengan perempuan. Tarian pa'gellu' memunculkan pengalaman perempuan dalam menari yang sekaligus menyimbolkan makna kehidupan. Perempuan menari dalam perayaan kehidupan yang menggambarkan penerimaan kultur atau tradisi terhadap makna perempuan dalam ritual. Melalui ritus $\mathrm{ma}^{\prime}$ ' bua' kasalle, tarian pa'gellu' tidak terdistorsi dalam praktik budaya, justru tarian dilibatkan juga dimunculkan sebagai bagian kesatuan dari ritual. Tarian pa'gellu' menjadi bentuk keterwakilan posisi perempuan dalam gerakan-gerakan sakral yang menjadi berdaya positif karena perempuan diberi ruang untuk mengekspresikan dirinya.

Carmody dalam interpretasinya terhadap teologi feminis Kristen, menawarkan pencarian makna sebagai dasar pengalaman iman Kristen yang berproses pada potensi diri terhadap misteri Tuhan. ${ }^{27}$ Perspektif Carmody mengkonfirmasi aksi ritual dalam tarian sebagai jalan pencarian makna yang memberikan daya juang untuk setiap perempuan dalam pengalaman memahami kehidupan, mulai dari diri, relasi dengan orang lain, alam dan juga tentang penciptanya. Makna ritual akan kebersamaan atau kesatuan hidup menjadi makna utama yang ditunjukkan dalam tarian pa'gellu'. Kesatuan yang menghubungkan manusia dengan sesama juga manusia dengan penghormatan

\footnotetext{
${ }^{24}$ Carmody, Christian Feminist Theology, 23.

${ }^{25}$ Stewart, Sacred Woman Sacred Dance: Awakening Spirituality Through Movement and Ritual, 25.

26 Ibid., 16.

${ }^{27}$ Carmody, Christian Feminist Theology, 19-20.
} 
terhadap pencipta. Makna kesatuan hidup tidak berhenti ketika tarian selesai, melainkan terus berkembang menjadi proses dialogis melalui aksi tarian perempuan dalam tarian pa'gellu'.

\section{Nani dan Simbong Wujud Kesetaraan}

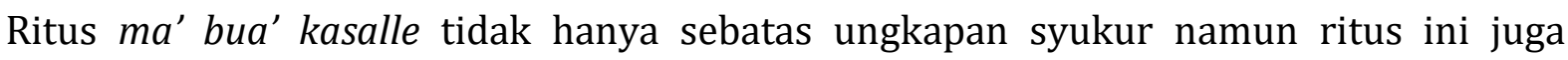
menampilkan aspek ritual yang menyentuh setiap lini kehidupan masyarakat. Dalam ritus $m a^{\prime}$ bua', terdapat kelompok penyanyi yaitu nani dan simbong sebagai representasi bahasa, pendukung jalannya ritual. Nani merupakan kategori yang mencakup tuturan yang disyairkan, diucapkan dengan nada datar atau dinyanyikan dan diperuntukkan bagi pujian, to menani adalah orang yang memuji, penanian adalah tempat nyanyian dilakukan yaitu dalam ritus $m a^{\prime}$ bua' yang melambangkan kesatuan sosial. ${ }^{28}$ Sedangkan simbong sepadan dengan nani, bedanya ialah simbong berisi kaum laki-laki. Laki-laki berada di sebelah lumbung dan perempuan di sebelah rumah. Meskipun dalam wujud tempat mereka berlawanan, tubuh mereka tak saling bersentuhan, tetapi suara-suara mereka saling menyatu dalam polimusik yang padu. ${ }^{29}$ Menariknya, nani dan simbong diwakilkan secara terpisah oleh perempuan dan laki-laki. Akan tetapi keduanya terlibat dalam harmonisasi suara yang sama, suara laki-laki dan perempuan menciptakan energi dan intensitas vokal dalam ritus $\mathrm{ma}^{\prime}$ 'bua' kasalle.

Dalam pelaksanaan menani dan manimbong ${ }^{30}$ masing-masing penyanyi diberikan kesempatan untuk menyanyi dan tidak bersamaan sehingga ada waktu jeda dari masingmasing kelompok bernyanyi. Nani dan simbong juga menjadi representasi sekaligus medium yang menghubungkan manusia dengan roh-roh leluhur dan deata. Kehadiran nani dan simbong sama pentingnya dengan persembahan kurban yang ada dalam ritus $m a^{\prime}$ bua'. Dengan menggunakan pendekatan etnomusikologi, Rappoport menemukan bahwa pengetahuan masyarakat Toraja dituangkan melalui tuturan ritual yang khas dalam syair-syair dan nyanyian-nyanyian, bukan dalam tulisan-tulisan ilmiah maupun ciptaan kesusasteraan dari lontar, bambu, atau kertas. ${ }^{31}$ Kajian Rappoport terhadap musik Toraja menunjukkan bahwa syair atau nyanyian dalam ritual budaya Toraja menjadi simbol bahasa dalam memaknai dunia, sebuah gambaran dunia yang tidak lepas dari keberadaan manusia, hewan, tumbuh-tumbuhan maupun tentang Tuhan.

Nani dan simbong menjadi salah satu bahasa ritual dalam ritus ma' bua' kasalle yang melengkapi aksi, objek dan ruang ritual. Dalam uraiannya tentang bahasa sebagai elemen dalam ritual, Grimes menunjukkan bahwa suara seringkali membentuk bahasa

\footnotetext{
${ }^{28}$ Rappoport, Nyanyian Tana Diperciki Tiga Darah: Penceritaan Etnografi, 79.

29 Ibid., 168.

30 Orang yang memuji dengan syair simbong

31 Dana Rappoport, Nyanyian Tana Diperciki Tiga Darah: Bunga Rampai Toraja, trans. oleh Stanislaus Sandarupa (Jakarta: Yayasan Pustaka Obor Indonesia, 2020), 25.
} 
ritual yang menimbulkan resonansi simpatik pada objek, termasuk tubuh manusia. ${ }^{32}$ Kehadiran suara melalui ritual menyimbolkan bahasa sebagai, bentuk komunikasi yang mampu membawa objek juga aktor dalam situasi sosial yang sama. Suara tidak hanya memengaruhi makna ritual, tetapi juga berdampak pada komunikasi antar pelaku dan elemen ritual yang lainnya seperti objek, tempat, aksi, dan kelompok-kelompok yang berpartisipasi. Pada ritus ma' $^{\prime}$ ua' $^{\prime}$ kasalle, bahasa nani dan simbong menghadirkan suara perempuan dan laki-laki dalam resonansi kesetaraan. Nani menjadi tidak lengkap atau tidak berarti tanpa adanya simbong begitu pun sebaliknya. Keduanya berbeda namun saling bergantung dan melengkapi. Ritus tersebut menciptakan seni suara secara seimbang.

Carmody mengartikan equality dalam membangun teologi konstruktif feminis Kristen sebagai pengakuan penuh terhadap eksistensi manusia, perempuan dapat menunjukkan ciri khas dalam pengalamannya untuk memaknai kehidupan religius. ${ }^{33}$ Perspektif teologis Carmody menguatkan makna bahasa ritual yang moderat, tidak menjadi radikal terhadap salah satu suara melainkan secara bersama mengakui suara perempuan dan laki-laki sebagai bangunan bahasa ritual. Nani dan simbong kemudian memungkinkan individu dalam pencarian akan cinta. Karena, pada dasarnya bahasa mengambil bentuk dalam ragam pengalaman. Bahasa pengalaman iman melalui pencarian akan cinta menunjukkan kekuatan yang paling ilahi, yang mewujud dalam kebebasan pengalaman manusia untuk mengekspresikan diri melalui kata-kata. ${ }^{34}$ Pengalaman tubuh yang mencari cinta melalui nyanyian dan pengalaman iman menunjukkan bahwa bahasa ritual merupakan strategi yang mengomunikasikan relasi tanpa batas, antara manusia dengan alam dan manusia dengan Tuhan.

Kehadiran suara perempuan dan laki-laki dalam ritus $\mathrm{ma}^{\prime}$ bua' kasalle secara implisit menghasilkan ruang pertemuan bagi pengalaman tubuh untuk mencapai tujuan ritual. Suara melalui syair atau nyanyian dapat menjadi bahasa yang membuka akses kepada perempuan agar menyampaikan keinginan, harapan dan siapa diri mereka. Keberterimaan terhadap suara perempuan dalam ritual kehidupan sama dengan keberterimaan akan pengalaman perempuan. Tamara Beauboeuf-Lafontant, seorang womanis asal DePauw University Amerika Serikat, dengan pendekatan naratif terhadap pengalaman perempuan kulit hitam, menemukan bahwa melalui pengalaman dan suara yang hidup memungkinkan perempuan untuk berpindah dari penderitaan juga perasaan terabaikan, kepada perjuangan akan kehidupan. ${ }^{35}$ Beauboeuf-Lafontant menunjukkan bahwa ketika suara perempuan muncul dalam realitas sosial yang merendahkan dan meminggirkan perempuan. Suara itu menjadi bentuk pengakuan akan kehadiran

${ }^{32}$ Grimes, The Craft of Ritual Studies, 275.

${ }^{33}$ Carmody, Christian Feminist Theology, x.

34 Ibid., 27.

35 Tamara Beauboeuf-Lafontant, Behind the Mask of the Strong Black Woman: Voice and the Embodiment of a Costly Performance (Philadelphia: Temple University Press, 2009), 139. 
pengalaman perempuan yang kemudian menjadi langkah awal dalam perjuangan akan kehidupan. Menurut penulis, bahasa melalui nani dan simbong dalam ritual tidak berarti menutupi eksistensi perempuan dalam budaya, melainkan suara menjadi media untuk menghidupkan pengalaman perempuan dengan segala bentuk keberadaannya.

\section{Tumbang di Menara Tinggi sebagai Bentuk Penghormatan Perempuan}

Perempuan yang mengambil peran bersama dengan pemangku adat dalam ritus $\mathrm{ma}^{\prime} \mathrm{bua}^{\prime}$ kasalle disebut tumbang. Salah seorang tumbang dikhususkan untuk berada di menara atau bagian atas Tongkonan jika pelaksanaan ritus ini dilakukan disekitar rumah adat. Dalam narasi yang ditemukan oleh Rappoport ada pengalaman yang melibatkan perempuan digendong untuk menuju ke menara tinggi. Grimes dalam melihat elemen tempat pada ritual menggambarkan bahwa lokasi pelaksanaan sebuah ritual memiliki "valensi simbolis yang tidak dapat diabaikan, preposisi memiliki konsekuensi dalam membentuk tindakan ritual". ${ }^{36}$ Penempatan ruang ritual tidak dibentuk tanpa adanya sesuatu yang telah dikonseptualisasikan, sehingga ada strategi yang mendahului pembentukan lingkungan yang berarti bahwa ruang ritual menjadi sejalan dengan tindakan ritual yang ingin dicapai. Grimes ingin menguatkan bahwa lokasi ritual menjadi bagian utama yang mendukung prosesi ritual karena lokasi bisa menciptakan nilai simbolis termasuk dalam perhatian pada preposisi dari aktor-aktor ritual. Melalui ritus $m a^{\prime}$ bua' kasalle, ragam preposisi yang ditunjukkan oleh to menani dan to manimbong terhadap posisi yang dikhususkan kepada tumbang. Meskipun terdapat perbedaan letak posisi dari masing-masing penyanyi, namun lokasi ritual menunjukkan sebuah nilai simbolis akan kehadiran perempuan dalam ritual kehidupan.

Posisi perempuan yang berada di atas menara tinggi atau di atas Tongkonan juga terkait dengan keyakinan masyarakat Toraja terhadap Tongkonan yang bukan sekadar rumah adat. Tongkonan di sebelah selatan melambangkan perempuan, dan alang (lumbung padi) di sebelah utara melambangkan laki-laki. ${ }^{37}$ Perempuan di tempatkan pada preposisi di atas Tongkonan atau menara sebagai bentuk penghormatan, karena melalui perempuan, keturunan dan sifat keluarga semakin berkembang luas. Pada sisi yang lain, rumah Tongkonan juga menyimbolkan kesetaraan baik peran laki-laki maupun perempuan, metafora Tongkonan dengan lumbung menjadi saling terikat satu sama lain, bukan sebagai bagian yang terpisahkan. ${ }^{38}$ Kehadiran perempuan tumbang di atas menara tinggi tidak hanya menyimbolkan peran dan kedudukan perempuan, tetapi juga

${ }^{36}$ Grimes, The Craft of Ritual Studies, 257.

37 Dina Gasong dan Ikma Citra Ranteallo, "Mengajukan Pengetahuan Lokal Toraja untuk Menghadapi Kematian Ibu dan Bayi," dalam Prosiding PKWG Seminar Series: Kebijakan Kesehatan dan Pelibatan Komunitas Dalam Menurunkan AKI/AKB di Indonesia, ed. oleh Khaerul Umam Noer (Jakarta: Pusat Kajian Wanita dan Gender Universitas Indonesia, 2015), 240.

38 Johana R Tangirerung, Selvi Panggua, dan Dina Gasong, "Menemukan Nilai-nilai Kesetaraan Jender dibalik Metafora Simbolik Rumah Adat 'Tongkonan'dan Lumbung 'Alang' Toraja” 3 (2020): 413-14. 
menggambarkan nilai pengakuan budaya terhadap jati diri perempuan dengan pengalaman tubuhnya. Makna simbolis perempuan tumbang akan berubah berdasarkan lokasinya, misalnya di dalam, di luar rumah atau lokasinya tidak disebutkan. Kekhususan posisi yang diberikan kepada seorang perempuan tumbang menyiratkan derajat sosial perempuan yang tinggi, karena menara dalam ritus-ritus budaya Toraja menjadi pusat dari jalannya aktivitas ritus.

Kehadiran perempuan tumbang sebagai aktor ritual menjadi upaya keadilan dalam gender yang sebagian besar didominasi oleh laki-laki. Grimes memaknai aktor ritual sebagai agen ritual yang sekaligus makhluk sosial. Aktor manusia adalah mereka yang dilibatkan baik secara marginal atau terpusat. ${ }^{39}$ Aktor bertindak untuk mencapai tujuan ritual, terlibat dengan eksistensinya yang menandakan kehadiran mereka dalam ritual. Dalam ritus $m a^{\prime}$ bua' kasalle, setiap orang dengan berbagai latar belakang terlibat secara bersama-sama tanpa memandang rupa. Namun, aktor ritual atau mereka yang bertugas dalam ritual tersebut ditentukan berdasarkan pada klasifikasi sosial seseorang. Pemilihan aktor perempuan tumbang tidak dilakukan secara acak tetapi ada keyakinan yang telah terkonsep dalam memandang perempuan secara kultural bahwa perempuan menjadi simbol persatuan keluarga serta keturunan dalam Tongkonan. Nilai simbolis penghormatan terhadap perempuan menjadi ruang kebebasan yang mewujudkan keadilan sosial dalam ritual budaya.

Carmody menguraikan bentuk pengalaman iman yang sejalan dengan gambaran feminisme yaitu pencarian keadilan. Keadilan menjadi pencarian religius tertinggi yang menciptakan keseimbangan, keadaan yang membentuk penerimaan dan pemberian secara adil, benar dan pantas. ${ }^{40}$ Carmody melibatkan konsep iman Kristen yang inklusif terhadap pengalaman perempuan. Pencarian keadilan tidak berarti meminggirkan lakilaki dan mengutamakan perempuan, tetapi keadilan merujuk pada penerimaan pengalaman perempuan yang selama ini termarjinalkan dalam teologi Kristen tradisional. Adanya tempat, lokasi yang melibatkan perempuan dalam ritual, telah menghasilkan lokasi sosial yang berkeadilan terhadap perempuan melalui ritus ma' bua' kasalle. Ritus ini mempertahankan perempuan sebagai aktor tumbang yang mewakilkan wujud penghormatan terhadap perempuan.

\section{Pengalaman Perempuan: Sebuah Konstruktif Teologis-Feminis}

Kekerasan terhadap perempuan dapat terjadi kapan pun dan berpeluang terjadi dalam ruang lingkup ritus. Kekerasan menjadi sulit diketahui ketika kekerasan dibungkam dengan pergeseran budaya yang juga didukung oleh dominasi budaya patriakat. Makalah ini menunjukkan ritus $m a^{\prime} b u a^{\prime}$ kasalle sebagai dasar kajian untuk melihat pengalaman tubuh perempuan dalam ritus menjadi kesepadanan dengan pengalaman iman yang

\footnotetext{
${ }^{39}$ Grimes, The Craft of Ritual Studies, 249.

40 Carmody, Christian Feminist Theology, 12.
} 
konstruktif dalam teologi feminis Kristen. Perempuan tidak hanya dilibatkan melalui tarian, tetapi juga dalam nyanyian. Ritus $m a^{\prime}$ bua' kasalle menampilkan kompleksitas dari kehadiran pengalaman perempuan Toraja dalam merayakan kehidupan. Kompleksitas merujuk pada pertemuan kelas dan status sosial dari perempuan-perempuan Toraja yang terlibat dalam pelaksanaan ritus, baik mereka yang berasal dari kelas sosial biasa maupun dari kelas bangsawan. Dalam hal ini, pengalaman perempuan Toraja yang menjadi sebuah tawaran teologi feminis dilakukan melalui analisis interseksionalitas antara kelas dan status sosial. Kemudian penulis melihat pengalaman perempuan dalam nilai kesetaraan melalui kisah dan pengajaran Yesus. Konsep pengalaman perempuan menjadi sumber refleksi terhadap dialog kebudayaan dengan teologi feminis.

\section{Pengalaman yang Memberdayakan}

Keterlibatan pengalaman perempuan Toraja dalam ritus $m a^{\prime} b u a^{\prime}$ kasalle menunjukkan sebuah interseksionalitas kelas sosial yang terjalin di antara masing-masing perempuan yang memiliki peran berbeda-beda. Amanda Burgess-Proctor, seorang ahli kriminologi feminis dari Oakland University, melihat interseksionalitas menandai sistem kekuasaan seperti ras, kelas, dan gender yang tidak bertindak sendiri untuk membentuk pengalaman manusia, melainkan sistem terkait erat dan dialami secara bersamaan. ${ }^{41}$ Sistem kekuasaan yang terbentuk pada kelas sosial menjadi terkait dengan identitas individu dalam pengalamannya sebagai bagian dari interseksionalitas. Dalam artian bahwa kajian interseksionalitas mengidentifikasi keterjalinan sistem kekuasaan yang mendominasi dalam pengalaman manusia untuk menunjukkan identitas sosial. Identitas baik laki-laki maupun perempuan dapat berubah ketika karakteristik ras juga kelas sosial dilekatkan pada individu yang hidup dalam kemajemukan masyarakat.

Dalam konteks ritus $m a^{\prime}$ bua' kasalle, interseksi yang terbentuk ialah relasi antara kelas, gender, dan status sosial yang terbentuk secara bersama-sama melalui tarian juga nyanyian. Interseksi kelas sosial merujuk kepada kelas bangsawan dengan kelas biasa yang relasinya tidak terpisahkan melainkan saling menyatu dalam ritual. Perempuan dari kelas bangsawan yang terlibat dalam praktik perempuan tumbang juga berinteraksi dengan perempuan-perempuan dari kelas biasa. Tidak ada larangan atau keharusan bagi perempuan tumbang untuk tidak terlibat dengan perempuan dari kelas sosial biasa. Interaksi yang tersirat dapat ditemui dalam keikusertaan perempuan tumbang untuk menyaksikan perempuan-perempuan dari kelas biasa melakukan tarian dan nyanyian. Nina Lykke, seorang ahli studi jender asal Norwegia, dalam A Guide to Intersectional

${ }^{41}$ Amanda Burgess-Proctor, "Intersections of Race, Class, Gender, and Crime: Future Directions for Feminist Criminology," Feminist Criminology 1, no. 1 (Januari 2006): 31, https://doi.org/ $10.1177 / 1557085105282899$. 
Theory, Methodology and Writing, mencoba untuk merekonstruksi makna interseksionalitas dengan berfokus pada kata inter menjadi intra.

Inter-action is something that goes on between bounded entities, clashing against each other like billiard balls, without initiating mutual transformations. Conversely, intraaction refers to an interplay between non-bounded phenomena, which interpenetrate and mutually transform each other. ${ }^{42}$

Secara implisit Lykke menunjukkan bahwa dalam kajian interseksionalitas, sebuah relasi yang terjalin antara kategori atau identitas sosial lebih kepada proses transformasi secara timbal balik. Setiap entitas berada dalam masing-masing perbedaan yang terikat, tetapi makna keterikatan bukan sebagai pemisah, melainkan sebagai proses konstruksi. Kata inter merujuk hanya pada pertemuan entitas tetapi tidak menghasilkan upaya transformasi, sedangkan makna intra mencakup perubahan yang juga dibentuk dalam pertemuan setiap entitas. Kemudian, interseksi sosial menjadi sebuah pertemuan yang bisa menghasilkan transformasi, ataupun sebaliknya, saling berbenturan. Pertemuan kategori atau sistem sosial seperti kelas, status maupun jender juga berarti tidak dapat dipisahkan dari pola relasi antara inter dan intra. Dalam ritus ma' bua' kasalle, pengalaman perempuan Toraja yang tidak lepas dari kategori kelas sosial antara bangsawan dan kelas biasa, menunjukkan sebuah pola intra-action yang memberdayakan diri dan komunitas. Pertemuan akan perbedaan kelas sosial dalam praktik ritual tidak menjadi berbenturan, justru setiap perempuan Toraja dapat mengolah potensi-potensi yang dimiliki seperti dalam nyanyian dan tarian. Selain memberdayakan diri, perempuan Toraja yang terlibat dalam ritus $m a^{\prime}$ bua' kasalle juga mengembangkan potensi yang dimiliki dengan komunitas di sekitar. Kehadiran para penari $p^{\prime}$ 'gellu', para penyanyi nani dan simbong juga dihasilkan melalui kelompok-kelompok pelatihan sehingga memberikan dampak yang positif bagi perkembangan seni tradisional dalam masyarakat Toraja.

Selanjutnya, pengalaman perempuan Toraja dalam ritus $m a^{\prime} b u a^{\prime}$ kasalle menjadi sebuah pengalaman yang menampilkan eksistensi diri dari perempuan sebagai bagian dari subjek atau aktor dalam ritual. Meskipun berasal dari kelas sosial yang berbeda, setiap perempuan dengan pengalamannya justru memiliki kebebasan untuk mengekspresikan diri melalui kemampuan yang dimiliki. Tidak ada pengekangan terhadap potensi perempuan, secara khusus dalam keterlibatan sebagai penari dan penyanyi. Selain itu, pengalaman perempuan Toraja diberi ruang untuk mengkomunikasikan atau merepresentasikan makna ungkapan syukur dari ritus $\mathrm{ma}^{\prime} \mathrm{bua}^{\prime}$ kasalle. Perempuan dengan eksistensi dirinya menjadi simbol keterwakilan masyarakat dalam penghormatan terhadap deata, sehingga pengalaman perempuan semakin konstruktif karena dilibatkan sebagai subjek atau aktor ritual yang utama. Pada posisi ini,

42 Nina Lykke, Feminist Studies: A Guide to Intersectional Theory, Methodology and Writing, Routledge Advances in Feminist Studies and Intersectionality 1 (New York: Routledge, 2010), 51. 
sumber pemberdayaan diri dan komunitas dihasilkan melalui pengalaman perempuan Toraja yang terjalin dalam interaksi antara kelas bangsawan dengan kelas biasa. Leah $\mathrm{R}$. Warner dan Stephanie A. Shields sebagai ahli psikologi melihat interseksionalitas dari sudut pandang yang berbeda. Interseksional memengaruhi pengalaman individu terhadap lingkungan dan pada tingkat sosio-struktural, status individu atau sumber daya sosial dapat menguntungkan atau meminggirkan karena terjadinya konvergensi identitas. ${ }^{43}$ Perspektif Warner dan Shields menegaskan bahwa interaksi yang terjadi antara individu dari kategori sosial yang berbeda menghasilkan dua dampak sosial yaitu relasi berdaya positif atau ketidaksetaraan. Dalam konsep interseksional, konstruksi sosial terhadap individu membentuk sistem yang tidak setara. Akan tetapi pada perwujudannya, interseksionalitas juga bergantung pada proses interaksi atau relasi.

Pada konteks ritus $\mathrm{ma}^{\prime}$ bua' kasalle, penulis melihat bahwa dari interaksi kelas sosial bangsawan dengan kelas sosial biasa telah menghasilkan pengalaman komunitas pada kesatuan. Kesatuan menggambarkan interaksi yang saling memberdayakan dan saling mendukung. Hal ini menjadi sejalan dengan sistem kekerabatan yang dianut oleh masyarakat Toraja yaitu kekerabatan bilateral. Dalam sistem kekerabatan bilateral ada nilai kesetaraan sehingga masyarakat dalam relasi saling melengkapi. 44 Meskipun perayaan ritus $\mathrm{ma}^{\prime}$ bua' kasalle hanya dilakukan oleh kelas sosial bangsawan, tetapi pengalaman perempuan dari kelas sosial biasa juga memberikan kontribusi yang signifikan dalam pelaksanaan ritus ini. Interaksi yang tercipta ialah saling melengkapi satu sama lain. Selain itu, melalui elemen bahasa ritual yang muncul dalam nani dan simbong menunjukkan kesetaraan suara antara perempuan dan laki-laki. Suara nyanyian menjadi sebuah medium pencarian cinta yang tidak terbatas. Syair identik dengan suara yang menghidupkan, memberi daya juang bagi perempuan dalam menampilkan eksistensi dirinya. Pada situasi tersebut, kekerasan tidak terjadi karena ritus ini dilakukan hanya ketika keluarga telah siap atau telah mencapai batasan yang sesuai dengan kelas sosialnya. Kemudian, pengalaman perempuan Toraja dalam ritus $\mathrm{ma}^{\prime} \mathrm{bua}^{\prime}$ kasalle menjadi pengalaman yang berdaya positif, menciptakan pengalaman akan keindahan, keadilan, dan makna relasi yang saling membangun.

\section{Pengalaman Perempuan Dalam Perjumpaan Dengan Yesus}

Pengalaman perempuan Toraja dalam ritus $\mathrm{ma}^{\prime}$ bua' kasalle' menggambarkan keterbukaan terhadap peran perempuan di tengah budaya masyarakat. Nilai keterbukaan mendorong terjadinya nilai kesetaraan yang tidak meminggirkan perempuan secara

\footnotetext{
${ }^{43}$ Leah R. Warner dan Stephanie A. Shields, "The Intersections of Sexuality, Gender, and Race: Identity Research at the Crossroads," Sex Roles 68, no. 11-12 (Juni 2013): 804, https://doi.org/10.1007/s11199-013-0281-4.

44 Tangirerung, Panggua, dan Gasong, "Menemukan Nilai-nilai Kesetaraan Jender dibalik Metafora Simbolik Rumah Adat 'Tongkonan'dan Lumbung 'Alang' Toraja," 409.
} 
khusus mereka yang berasal dari kelas sosial biasa. Pengalaman perempuan menjadi sumber teologis untuk melihat bahwa perempuan melalui eksistensi dirinya dapat menghubungkan penghormatan terhadap Tuhan. Eksistensi diri ialah pengalaman dalam menari, menyanyi bahkan dalam relasi yang setara. Dalam tradisi kitab suci Kristen, kehadiran pengalaman perempuan sebenarnya kurang diberi perhatian karena perempuan ditempatkan pada posisi kedua. Neston Sidauruk menggunakan pendekatan kualitatif untuk menyelidiki eksistensi perempuan dalam pelayanan Yesus. Bagi Sidauruk, adanya gap pemisah antara peran laki-laki dan perempuan dalam kepemimpinan maupun ritus-ritus kekristenan menandakan sebuah kesalahan karena tidak sesuai dengan teladan Yesus yang tidak mendistorsi pengalaman antara laki-laki dan perempuan. ${ }^{45}$ Perspektif Sidauruk ingin menegaskan bahwa sudah seyogianya ritus-ritus kekristenan, kepemimpinan iman Kristen terbuka terhadap eksistensi perempuan dengan pengalamannya. Kemudian, nilai keterbukaan terhadap pengalaman perempuan di Alkitab menjadi lebih relevan jika bersumber pada kisah dan pengajaran Yesus dalam Perjanjian Baru (PB). Pelayanan Yesus lebih memberikan sumber yang menjanjikan bagi peran pengalaman perempuan sebagai subjek yang penting.

PB berisikan sejumlah pelayanan Tuhan Yesus yang dekat dengan perempuan, bahkan Yesus menunjukkan penghargaan terhadap eksistensi perempuan. Penghargaan Yesus terhadap perempuan misalnya dapat dilihat dalam kisah Yesus diurapi oleh seorang perempuan di Betania (Mrk. 14:3-9, Yoh. 12:1-8). Pada saat itu, orang-orang melihat perempuan yang menggunakan minyak narwastu murni lalu mencurahkannya ke atas kepala Yesus sebagai tindakan pemborosan. Yesus justru menegaskan bahwa itu adalah perbuatan baik. Tindakan perempuan terhadap Yesus dapat dimaknai sebagai aksi ritual untuk menegaskan kemesiasan Yesus. ${ }^{46}$ Karakter ritual yang tersirat dalam tindakan perempuan tidak hanya memuat makna identitas Yesus. Akan tetapi, tindakan tersebut juga digunakan untuk menandai ingatan komunitas pada kehadiran Yesus melalui perempuan. Jawaban Yesus secara implisit menggambarkan penghargaan, penerimaan tindakan kasih dari perempuan. Dalam hal ini kisah pengurapan Yesus menampilkan ritual pada ruang keterbukaan akan pengalaman perempuan. Pada saat yang sama, pengalaman perempuan dengan Yesus menawarkan suatu makna kehadiran perempuan. Kehadiran yang melibatkan perempuan dengan segala keberadaan dirinya, eksistensinya termasuk iman, perspektif dan kehadirannya sebagai upaya kesetaraan, keadilan dalam melakukan ritual. Sejalan dengan nilai kesetaraan dalam ritus $\mathrm{ma}^{\prime}$ ' bua' kasalle, bahwa pengalaman perempuan bukan hanya sebagai pelengkap, melainkan sebagai aktor ritual yang memengaruhi jalannya ritus. Perjumpaan Yesus dengan

\footnotetext{
${ }^{45}$ Neston Sidauruk, “Eksistensi Perempuan Dalam Paradigma dan Pelayanan Yesus,", Jurnal Teologi Cultivation 3, no. 2 (18 Desember 2019): 1, https://doi.org/10.46965/jtc.v3i2.272.

${ }^{46}$ Santiago Guijarro dan Ana Rodríguez, "The 'Messianic' Anointing of Jesus (Mark 14:3-9)," Biblical Theology Bulletin: Journal of Bible and Culture 41, no. 3 (Agustus 2011): 141, https://doi.org/10.1177/0146107911413210.
} 
pengalaman perempuan menjadi relevan dengan kehadiran perempuan dalam ritual budaya Toraja. Bahwa Yesus tidak menghalangi kehadiran perempuan dalam eksistensinya untuk meminyaki Yesus dengan minyak yang mahal. Teladan Yesus menjadi praktik budaya yang relevan untuk mengarahkan pengalaman perempuan pada perjuangan kesetaraan.

Kemudian, makna kehadiran perempuan dalam pelayanan Yesus juga menjadi kajian dari penulisan Hans Küng (1928-2021). "Jesus dissociated himself from the customary exclusion of women, not only does Jesus show no contempt for women; he is amazingly open towards them." 47 Kung menunjukkan bahwa karakter Yesus terhadap perempuan merupakan bernilai penerimaan, menunjukkan kesetaraan untuk tidak mendiskriminasi perempuan. Perempuan tidak dimarginalkan dengan eksistensinya, justru Yesus melibatkan diri dengan pengalaman perempuan dalam budaya yang di dominasi oleh budaya patriakat. Beberapa kisah perempuan yang dituliskan dalam Perjanjian Baru memiliki relasi yang dekat dengan Tuhan Yesus. Seperti Maria dan Marta (Luk. 10:38-42), Maria Magdalena (Luk. 8:2), perempuan Kanaan yang percaya (Mat. 15:21-28), Yesus dengan perempuan Samaria (Yoh. 4:1-42), Yesus dengan perempuan yang berzinah (Yoh. 8:12-20). Sidauruk melihat kehadiran para perempuan dalam kisah pelayanan Yesus menunjukkan peran perempuan dalam relasi yang terhormat dan layak, meskipun beberapa perempuan berasal dari golongan masyarakat biasa. ${ }^{48}$ Perjumpaan Yesus dengan perempuan yang termarjinalkan oleh konsep budaya Yahudi menjadi sebuah interseksionalitas yang mentransformasi identitas perempuan. Peran perempuan yang tadinya tidak diberi ruang, sekarang berubah menjadi penghargaan. Interseksionalitas pengalaman perempuan dari kelas sosial biasa menjadi tampak dalam pelayanan Yesus. Berbagai pengalaman interaksi yang ditunjukkan Yesus mampu mengubah kehidupan para perempuan, bahwa identitas sosial mereka tidak lagi dimaknai sebagai standar untuk mendapatkan penerimaan diri di depan Yesus.

Berangkat dari perjumpaan Yesus dengan pengalaman perempuan, maka nilai inklusif, nilai kesetaraan dapat dimaknai ketika perempuan tidak dimarginalkan dari realitas budaya. Dalam ritus $m a^{\prime}$ bua' kasalle, pengalaman perempuan Toraja juga diperhadapkan pada relasi kelas sosial. Akan tetapi, peran perempuan justru berada pada pengalaman yang saling melengkapi. Perempuan dengan eksistensinya dalam tindakan menari dan menyanyi. Tarian dan nyanyian yang ada dalam aksi ritus ma' bua' kasalle menjadi simbol pengalaman perempuan yang membuka ruang keadilan, kesetaraan serta kebebasan bagi perempuan untuk tidak lagi terpinggirkan. Marc Lafrance seorang ahli sosiologi dan antropologi dari Concordia University menggunakan pendekatan

47 Hans Küng, Women in Christianity, trans. oleh John Stephen Bowden (London; New York: Continuum, 2005), 2.

48 Sidauruk, "Eksistensi Perempuan Dalam Paradigma dan Pelayanan Yesus," 2. 
psikoanalisis, melihat metafora kulit sebagai tubuh pertama manusia yang dapat merasakan diri sekaligus memisahkan diri dengan orang lain. Pengalaman tubuh menegosiasikan ruang asing yang tidak hanya terikat pada mental dan fisik, tetapi terikat pada sosial, budaya dan sejarah. ${ }^{49}$ Melalui pengalaman tubuh yang tidak dipisahkan dari interaksi sosial, perempuan dapat dimungkinkan untuk bersuara, berjuang dan mendapatkan kesempatan dalam potensi dirinya. Pengalaman perempuan bukan hanya merujuk pada bahasa perempuan dalam ritual, tetapi juga kehadiran perempuan itu sendiri secara fisik. Ritual menjadi seimbang juga dapat mencegah ruang ketertindasan, kekerasan baik bagi perempuan maupun laki-laki.

Pengalaman perempuan kemudian dapat menjadi lokasi sosial yang memungkinkan adanya kebebasan ekspresi pengalaman tubuh. Carmody menawarkan gereja sebagai komunitas Kristen sekaligus menjadi lokasi sosial untuk melihat karya penebusan dan rahmat ilahi di dalam Kristus yang penuh kasih dan mampu membebaskan. ${ }^{50}$ Gagasan Carmody memberikan peluang dalam pengalaman iman yang kaya akan pengalaman perempuan, ketika Kristus diletakkan dalam terang iman yang membebaskan setiap orang dalam komunitas yang setara untuk merayakan kehidupan. Menurut penulis, jika pengalaman iman dibebaskan dalam pemaknaan akan Tuhan, maka perspektif pengalaman perempuan menjadi ruang kebebasan dalam ritual. Karena, ritual sendiri adalah pengalaman tubuh yang dinamis sehingga setiap individu, perempuan dan laki-laki dapat berpartisipasi secara setara. Grimes dalam teori ritual menuliskan "people do it, and they do it in overt, bodily ways, because it is in and of bodies, ritual is also cultural, since bodies are enculturated." ${ }^{\prime 51}$ Grimes menekankan bahwa ritual pada dasarnya adalah pengalaman tubuh yang tidak dapat dilepaskan dari pengalaman budaya yang telah membentuk ritual menjadi bermakna. Dalam hal ini ketika ritual dipahami sebagai pengalaman tubuh maka perempuan dapat bersuara memberikan kehadirannya yang memiliki ragam pengalaman dan bahasa tubuh yang kreatif dan berdaya positif. Pengalaman perempuan menjadi sebuah perspektif yang merangkul kebersamaan, mengupayakan keseimbangan dan mewujudkan kesetaraan dalam praktik ritual budaya maupun dalam iman Kristen.

\section{Relevansi Pengalaman Perempuan Toraja}

Interseksionalitas pengalaman perempuan dalam ritus $m a^{\prime}$ bua' kasalle telah menghasilkan nilai-nilai kearifan lokal yang dapat digunakan sebagai perspektif teologis terhadap pertumbuhan gereja. Nilai kearifan lokal merujuk pada keindahan dalam tarian pa'gellu', nilai harmonisasi suara yang menyatukan nani dan simbong, hingga nilai penghargaan terhadap perempuan melalui tumbang. Nilai-nilai tersebut menunjukkan

49 Marc Lafrance, "Embodying the subject: Feminist theory and contemporary clinical psychoanalysis," November 2007, 267.

50 Carmody, Christian Feminist Theology, 127.

51 Grimes, The Craft of Ritual Studies, 195. 
bahwa budaya Toraja memiliki sumber yang relevan untuk membangun dialog kebudayaan dengan teologi. Penulis melihat bahwa konsep pengalaman perempuan Toraja sebagai aktor ritual menjadi sebuah upaya kesetaraan yang sebenarnya telah lama dibangun oleh leluhur-leluhur orang Toraja. Penulis setuju untuk menggunakan makna pengalaman perempuan Toraja dalam ritus ma' bua' kasalle yang kaya akan nilai kearifan lokal Toraja. Binsar Jonathan Pakpahan mengartikan kearifan lokal sebagai "cara mencapai dan mempertahankan harmoni dalam masyarakat yang sudah ada sejak leluhur mereka". ${ }^{52}$ Nilai kesetaraan, kesatuan, dan interaksi saling melengkapi yang terwujud melalui pengalaman perempuan Toraja menjadi upaya dalam membangun harmonisasi di tengah realitas budaya. Pengalaman perempuan Toraja juga dapat menjadi perspektif teologis untuk gereja dalam memaknai ruang kesetaraan antara perempuan dan laki-laki. Bahwa praktik kepemimpinan atau ritus ibadah dalam gereja dapat melibatkan bahasa, peran perempuan seperti tarian atau nyanyian.

\section{Kesimpulan}

Kekerasan dapat terjadi dalam ritual budaya yang tidak menghadirkan pengalaman perempuan sebagai pengalaman tubuh yang dinamis. Masalah ketidakadilan dan kekerasan dipengaruhi oleh menguatnya budaya patriarkat dalam dominasi terhadap perempuan. Sebab itu, diperlukan bangunan perspektif sebagai basis dialog kebudayaan dengan teologi feminis yang memperjuangkan kesetaraan dan keadilan. Praktik ritus $m a^{\prime}$ bua' kasalle sebagai ritual syukuran akan kehidupan menunjukkan sebuah praktik ritual budaya yang menghadirkan interseksionalitas pengalaman perempuan dalam ritual. Berdasarkan kajian dialogis antara pemikiran Grimes dan Carmody, terdapat beberapa penemuan yang memunculkan basis perspektif untuk memaknai teologi feminis dalam praktik ritual budaya, yaitu interseksionalitas pengalaman perempuan Toraja. Adapun beberapa interseksionalitas yang ditemukan dalam makalah ini ialah pertama pengalaman perempuan menyangkut pengalaman tubuh dalam menarikan tarian pa'gellu' yang memberikan makna simbolis bagi kehidupan bersama antara manusia, alam, dan Tuhan. Kedua, pengalaman perempuan melibatkan nyanyian, syair yang menghadirkan perempuan dan laki-laki dalam ruang kesetaraan, membangun relasi yang saling menyatu dalam suara melalui nani dan simbong. Ketiga, pengalaman perempuan terwujud dalam penempatan ruang yang dikhususkan kepada perempuan sebagai bentuk simbolis penghormatan terhadap perempuan. Pada akhirnya, interseksionalitas pengalaman perempuan Toraja dalam ritus $m a^{\prime}$ bua' kasalle menunjukkan sebuah perjumpaan interseksi antara kelas sosial bangsawan dengan kelas sosial biasa, antara

52 Binsar Jonathan Pakpahan, "Membangun Teologi Kontekstual dari Kearifan Lokal Toraja," dalam Teologi Kontekstual dan Kearifan Lokal Toraja, ed. oleh Binsar Jonathan Pakpahan (Jakarta: BPK, 2020), 14. 
laki-laki dengan perempuan. Perjumpaan yang justru saling melengkapi dan memberdayakan diri perempuan juga komunitas. Perjumpaan yang menjadi relevan dalam pengalaman perempuan dengan pelayanan Yesus. Bahwa pengalaman perempuan menjadi ruang kesetaraan yang juga ditunjukkan Yesus untuk merekonstruksi marginalisasi terhadap eksistensi perempuan. Pada akhirnya, tulisan ini dapat menjadi dasar bagi perkembangan akan penelitian selanjutnya yang menghubungkan realitas kebudayaan dengan teologi feminis.

\section{Referensi}

Beauboeuf-Lafontant, Tamara. Behind the Mask of the Strong Black Woman: Voice and the Embodiment of a Costly Performance. Philadelphia: Temple University Press, 2009. https://www.goodreads.com/book/show/9376123-behind-the-mask-ofthe-strong-black-woman.

Berry, Jan. "Whose Threshold? Women's Strategies of Ritualization." Feminist Theology 14, no. 3 (Mei 2006): 273-88. https://doi.org/10.1177/0966735006063769.

Buijs, Kees. To Burake Imam Perempuan Pelayan Adat Tertinggi: Ritual dan Ucapannya dalam Agama Tradisional Masyarakat Toraja Mamasa. Disunting oleh Anwar Jimpe Rachman. Makassar: Ininnawa, 2020.

Burgess-Proctor, Amanda. "Intersections of Race, Class, Gender, and Crime: Future Directions for Feminist Criminology." Feminist Criminology 1, no. 1 (Januari 2006): 27-47. https://doi.org/10.1177/1557085105282899.

Carmody, Denise L. Christian Feminist Theology: A Constructive Interpretation. Cambridge: University of California Press, 1995.

Demmallino, Eymal B. Utang budaya perempuan Tana Toraja. Kerja sama Ford Foundation dengan Pusat Studi Kependudukan dan Kebijakan, Universitas Gadjah Mada, Yogyakarta, 2004.

Denzin, Norman K, dan Yvonna S Lincoln. The SAGE Handbook of Qualitative Research. California: SAGE Publications, 2018.

Gasong, Dina, dan Ikma Citra Ranteallo. "Mengajukan Pengetahuan Lokal Toraja untuk Menghadapi Kematian Ibu dan Bayi." Dalam Prosiding PKWG Seminar Series: Kebijakan Kesehatan dan Pelibatan Komunitas Dalam Menurunkan AKI/AKB di Indonesia, disunting oleh Khaerul Umam Noer. Jakarta: Pusat Kajian Wanita dan Gender Universitas Indonesia, 2015.

Grimes, Ronald L. Deeply into the Bone: Re-Inventing Rites of Passage. Life Passages. Berkeley: University of California Press, 2000.

- - - The Craft of Ritual Studies. Oxford ; New York: Oxford University Press, USA, 2013.

Guijarro, Santiago, dan Ana Rodríguez. “The 'Messianic' Anointing of Jesus (Mark 14:39)." Biblical Theology Bulletin: Journal of Bible and Culture 41, no. 3 (Agustus 2011): 132-43. https://doi.org/10.1177/0146107911413210. 
Küng, Hans. Women in Christianity. Diterjemahkan oleh John Stephen Bowden. London ; New York: Continuum, 2005.

Lafrance, Marc. "Embodying the subject: Feminist theory and contemporary clinical psychoanalysis," November 2007.

Lykke, Nina. Feminist Studies: A Guide to Intersectional Theory, Methodology and Writing. Routledge Advances in Feminist Studies and Intersectionality 1. New York: Routledge, 2010.

Pakpahan, Binsar Jonathan. "Membangun Teologi Kontekstual dari Kearifan Lokal Toraja." Dalam Teologi Kontekstual dan Kearifan Lokal Toraja, disunting oleh Binsar Jonathan Pakpahan, 1-18. Jakarta: BPK, 2020.

Komnas Perempuan | Komisi Nasional Anti Kekerasan Terhadap Perempuan. "Pemetaan, Kajian, \& Prosiding." Diakses 10 November 2021. https://komnasperempuan.go.id/pemetaan-kajian-prosiding-detail/kekerasanterhadap-perempuan-berbasis-budaya.

Rappoport, Dana. Nyanyian Tana Diperciki Tiga Darah: Bunga Rampai Toraja. Diterjemahkan oleh Stanislaus Sandarupa. Jakarta: Yayasan Pustaka Obor Indonesia, 2020.

- - - Nyanyian Tana Diperciki Tiga Darah: Penceritaan Etnografi. Diterjemahkan oleh Stanislaus Sandarupa. Jakarta: Yayasan Pustaka Obor Indonesia, 2020.

Sari, Intan Matasak. “MAKNA SIMBOLIK PA'GELLU' TUA DI DESA PANGALA'KABUPATEN TORAJA UTARA'." Masters, Fakultas Seni dan Desain, 2020. http://eprints.unm.ac.id/19194/.

Sidauruk, Neston. "Eksistensi Perempuan Dalam Paradigma dan Pelayanan Yesus." Jurnal Teologi Cultivation 3, no. 2 (18 Desember 2019): 115-26. https://doi.org/10.46965/jtc.v3i2.272.

Stewart, Iris J. Sacred Woman Sacred Dance: Awakening Spirituality Through Movement and Ritual. Rochester: Inner Traditions, 2013. https://sacreddancer.com/about.htm.

Tangirerung, Johana R, Selvi Panggua, dan Dina Gasong. "Menemukan Nilai-nilai Kesetaraan Jender dibalik Metafora Simbolik Rumah Adat 'Tongkonan'dan Lumbung 'Alang' Toraja” 3 (2020): 12.

Theodorus Kobong. Injil dan Tongkonan: Inkarnasi, Kontekstualisasi, Transformasi -. Diterjemahkan oleh Th. van den End dan Theodorus Kobong. Cet. 2. Jakarta: BPK Gunung Mulia, 2020.

Warner, Leah R., dan Stephanie A. Shields. "The Intersections of Sexuality, Gender, and Race: Identity Research at the Crossroads." Sex Roles 68, no. 11-12 (Juni 2013): 803-10. https://doi.org/10.1007/s11199-013-0281-4. 